\title{
Investigation of the SHS process initiation in the base mixture during HFC heating and the dependence of the combustion rate on various factors
}

\author{
Vladimir Malikov ${ }^{1 *}$ and Alexey Ishkov ${ }^{2}$ \\ ${ }^{1}$ Altay State University, 656049, Barnaul, Russia \\ ${ }^{2}$ Altay State Agricultural University, 656049, Barnaul, Russia
}

\begin{abstract}
This work is devoted to the study of promising materials liquid-phase systems aluminum-boron oxide. These materials after SHS process form a boride coating that provides high strength and wear resistance of steel parts. The article describes the features of the initiated SHS process and the nature of the mixture combustion, studies of the HFC heating effect for SHS process. At the first research stage, the dependence of initiation SHS in all investigated compositions on the characteristic size of the sample and the composition of the base mixture was determined. The combustion rate was estimated from the combustion time of the sample from one end of the sample to the other. The burning rate was also estimated SHS-compositions on the particle size of the reagents. At the second stage of the research, the composition of the base mixture was modified by the introduction of a flux P-0.66. The addition of flux made it possible to significantly reduce the burning rate and compare in time SHS process obtaining boron during combustion of a modified composition and the process of HFC boriding high-speed.
\end{abstract}

\section{Introduction}

At present, all over the world, new multifunctional coatings are constantly being developed [1-4] for industrial applications in such industries as mechanical engineering, aviation and rocket and space propulsion, tool production, etc. The application of nanocomposite and multifunctional coatings that combine a unique structure and a combination of properties such as hardness, strength, thermal stability, heat resistance, wear resistance, as well as a relatively low coefficient of friction will dramatically increase the performance of various products and extend their service life [5-8]. One of the promising methods of obtaining such coatings is the method of self-propagating high-temperature synthesis.

The method of self-propagating high-temperature synthesis is a process of moving a wave of a chemical reaction through a mixture of reagents with the formation of solid final products, carried out with the aim of synthesizing substances of materials. SHS - a mode of a strong

*Corresponding author: osys11@gmail.com 
exothermic reaction (combustion reaction), in which heat release is localized in a layer and is transferred from layer to layer by means of heat transfer. This method has a number of advantages such as energy efficiency, fast process and high purity of final products. Method SHS Today, a large number of various materials based on oxide ceramics are obtained, both in the form of powders and in the form of compact workpieces [9]. For example, in [10], a ceramic powder was obtained based on an oxide eutectic $\mathrm{Al}_{2} \mathrm{O}_{3}-\mathrm{ZrO}_{2}$, strengthened by particles of zirconium diboride and tungsten boride. In $[11,12]$, as a result of the combination SHS dynamic compaction were obtained composites $\mathrm{Al}_{2} \mathrm{O}_{3}-\mathrm{ZrB}_{2}$ and $\mathrm{Al}_{2} \mathrm{O}_{3}-\mathrm{TiB}_{2}$ with high mechanical properties. In [13], using SHS and subsequent pseudo-HIP the compact ceramic samples based on $\mathrm{Al}_{2} \mathrm{O}_{3}-\mathrm{TiB}_{2}-\mathrm{TiC}$ were obtained with a bundle based on Fe. In work [14] SHS with microwave was used to obtain a composite powder $\mathrm{Al}_{2} \mathrm{O}_{3}-\mathrm{WC}$.

SHS reliable initiation in thermoactivated systems, the reaction products of which are used for further technological processes (obtaining finished ceramics, obtaining coatings, obtaining functional materials, workpieces, products, etc.) largely determine the very possibility of such technologies. Unreliable initiation, erratic and uncontrolled combustion can negate all efforts in the development of technologies based on SHS.

In this plan HFC heating, used to initiate SHS process, as well as in the further implementation of physicochemical transformations with the participation of its products and the material of the metal substrate, is a powerful control factor in the developed technology for obtaining hardening boride coatings.

Study of the stoichiometry and heating parameters influence on the chemical SHS products composition and combustion temperature had been carried out earlier [15]. The synthesis was carried out without external heating, due to which the final product was formed completely single-phase. By analyzing the resulting dependences of the temperature and combustion rate on the initial temperature, the activation energy was calculated. Its value turned out to be equal to $139.4 \mathrm{~kJ} / \mathrm{mol}$. The similar value was obtained in other experiments [16] $(167.2 \mathrm{~kJ} / \mathrm{mol})$. Combustion of the Mo - Si system was carried out in [17-21]. It was found that during the combustion process, layers of intermediate silicide are formed by reaction diffusion. At the same time, it is possible to obtain a layer on the surface of refractory particles (if the particles are large) or precipitate from the melt (if the refractory particles are very small) by changing the combustion conditions and the size of the reagent particles.

In [22], a study of the reaction occurring during synthesis in the combustion front was made. In this case, the results analysis of thermal properties was carried out with different time resolution in the combustion process. It was found that providing a low external heating rate, the combustion wave propagation is close to natural.

In this work, the combustion rate dependences on the composition of mixtures and the particle size of the reagents were experimentally investigated, and the effect of the flux introduced into the mixture was tested.

\section{Materials and methods}

The base mixture under study containing stoichiometric amounts of aluminum and boron (III) oxide according to the currently accepted classification SHS processes, refers to liquid-phase systems, in which the following stages are sequentially implemented: combustion (chemical transformation), phase separation and secondary processes (boriding), cooling of products and obtaining a coating.

In a combustion wave, a mixture of initial reagents $\mathrm{Al}+\mathrm{B}_{2} \mathrm{O}_{3}$ undergoes a number of physical and chemical transformations $[23,24]$. In this case, in the heating zone after the melting of the initial boron (III) oxide, a continuous liquid medium is formed in which $\mathrm{Al}$ particles (droplets) are spread. 
Chemical interaction in the studied systems at HFC heatinge is carried out in two stages.

At the first stage, at the beginning of the chemical transformation zone, droplets and particles interact with the initial oxide according to the following reaction:

$$
\mathrm{B}_{2} \mathrm{O}_{3}+2 \mathrm{Al}=2 \mathrm{~B}+\mathrm{Al}_{2} \mathrm{O}_{3}, \Delta H_{p}<0
$$

At the second stage, after the formation of free, active boron and $\mathrm{A}_{2}{ }_{2} \mathrm{O}_{3}$ there is a second reaction - a high-speed HFC boriding base metal by the reactions:

$$
\begin{gathered}
\mathrm{Fe}+\mathrm{B}=\mathrm{FeB}, \\
2 \mathrm{Fe}+\mathrm{B}=\mathrm{Fe}_{2} \mathrm{~B}, \\
4 \mathrm{Fe}+\mathrm{B}_{4} \mathrm{C}=4 \mathrm{FeB}^{\mathrm{C}}+\mathrm{C}, \\
3 \mathrm{Fe}+\mathrm{C}=\mathrm{Fe}_{3} \mathrm{C} ;
\end{gathered}
$$

As a result, two condensed products are formed: a boride coating and a crust. A12O3, and also gases can form: sublimated $\mathrm{B}_{2} \mathrm{O}_{3}$, metal vapors ( $\mathrm{Al}, \mathrm{Fe}$ ), and volatile sub- and super oxides $\left(\mathrm{BO}, \mathrm{BO}_{2}, \mathrm{~B}_{2} \mathrm{O}_{4}, \mathrm{~B}_{2} \mathrm{O}_{5}\right)$.

Gases released in the melt during combustion can lead to scatter (dispersion) of the melt, an increase in its porosity, expansion and decrease in the density of the SHS products, worsen the process initiation. However, in preliminary experiments and in the incineration of cylindrical shaped specimens, a slight increase in SHS process product volume in relation to the starting materials was noted. Therefore, gas formation in the stoichiometric system $2 \mathrm{Al}+\mathrm{B}_{2} \mathrm{O}_{3}\left(\mathrm{~m}\left(\mathrm{~B}_{2} \mathrm{O}_{3}\right) / \mathrm{m}(\mathrm{Al})=1 / 0.775\right)$ can be neglected, and all initiation (ignition) dependences and combustion rate will be determined only by the particle size, the ratio of reagents or the presence of inert components in the mixture.

\section{Research results}

Initially, the SHS process initiation by the local source of heating (nichrome spiral) in cylindrical molded samples, the composition of which differs from the stoichiometric excess $\mathrm{Al}$ or $\mathrm{B}_{2} \mathrm{O}_{3}$ was investigated. Mixtures of reagents were prepared for this with a mass ratio different from the stoichiometric (1/0.775) both to a large (excess of aluminum) and to a smaller side (excess of boron (III) oxide), from which the samples were formed. After drying, the height of the samples was measured and initiation of SHS process was carried out in them by heating the nichrome spiral $\varnothing 4-5 \mathrm{~mm}\left(q_{\text {ign. }}=100-150 \mathrm{~W} / \mathrm{cm}^{2}\right)$. The example of the obtained coating microstructure is shown in Fig. 1. The results of the tests are shown in Table 1.

Table 1. SHS process initiation in cylindrical molded samples from the base mix $\mathrm{Al}+\mathrm{B}_{2} \mathrm{O}_{3}$ point source

\begin{tabular}{|c|c|c|l|}
\hline $\begin{array}{c}\text { Mass ratio of } \\
\text { reagents }\end{array}$ & $\begin{array}{c}\text { Sample } \\
\text { height } \boldsymbol{L}, \mathbf{m m}\end{array}$ & $\begin{array}{c}\boldsymbol{t}_{\text {ign., }} \\
\mathbf{c}\end{array}$ & \multicolumn{1}{|c|}{$\begin{array}{c}\text { SHS initiation, } \\
\text { combustion pattern }\end{array}$} \\
\hline $1 / 0.1$ & 20 & - & not initiated \\
\hline $1 / 0.3$ & 15 & $3.0-3.3$ & triggered, unstable with food splashing \\
\hline $1 / 0.5$ & 20 & $1.8-2.5$ & initiated, slow intermittent \\
\hline $1 / 0.775^{*}$ & 22 & $1.0-1.3$ & triggered, fast steady \\
\hline $1 / 0.8$ & 17 & $2.5-2.7$ & triggered, fast steady \\
\hline $1 / 1$ & 15 & $3.5-4.5$ & initiated, rapid explosive \\
\hline $1 / 1.2$ & 12 & & not initiated \\
\hline $1 / 1.5$ & 15 & & not initiated \\
\hline
\end{tabular}

Note: * - stoichiometric composition. 


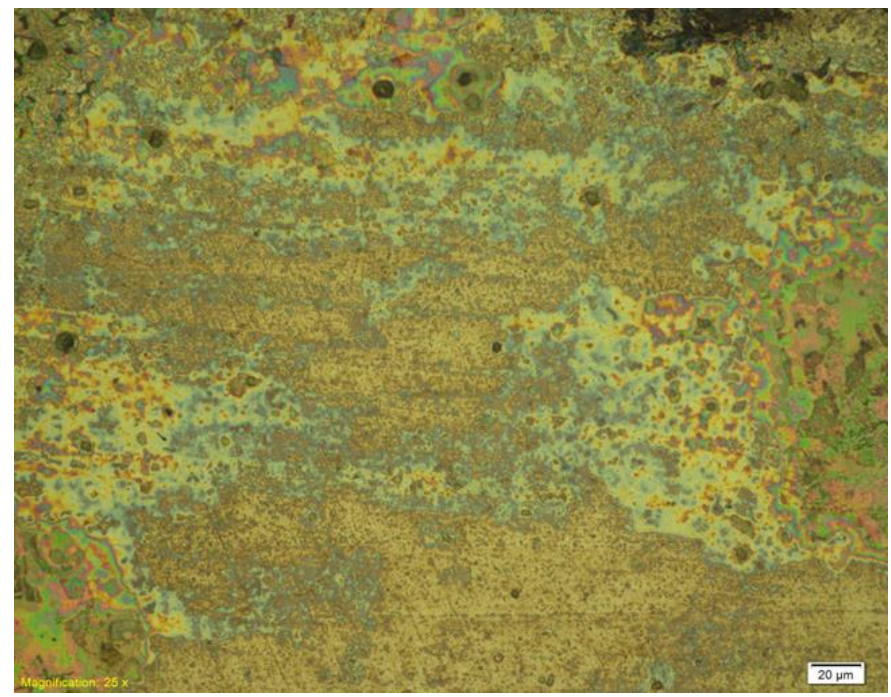

Fig. 1. The microstructure of the coating obtained during SHS process Sample 1

As follows from the data in Table 1, the specified thermal power of the point source $\left(100-150 \mathrm{~W} / \mathrm{cm}^{2}\right)$ is not enough to initiate SHS process in the base mixture as with an excess of boron oxide (III), and with an excess of aluminum, in addition, the combustion of mixtures with a ratio $\mathrm{m}\left(\mathrm{B}_{2} \mathrm{O}_{3}\right) / \mathrm{m}(\mathrm{Al}) 1 / 0.3 ; 1 / 0.5 ; 1 / 1$ in the form of the samples with a ratio of characteristic dimensions $L / d$ 1.5-2.2 is unstable and will be poorly managed technologically.

On SHS process initiation in similar samples by the heat released at HFC heatinge steel plates $65 \mathrm{G}$, the size $50 * 100 * 5 \mathrm{~mm}$, the following results were obtained (Table 2). An example of the microstructure of the obtained coating is shown in Fig. 2.

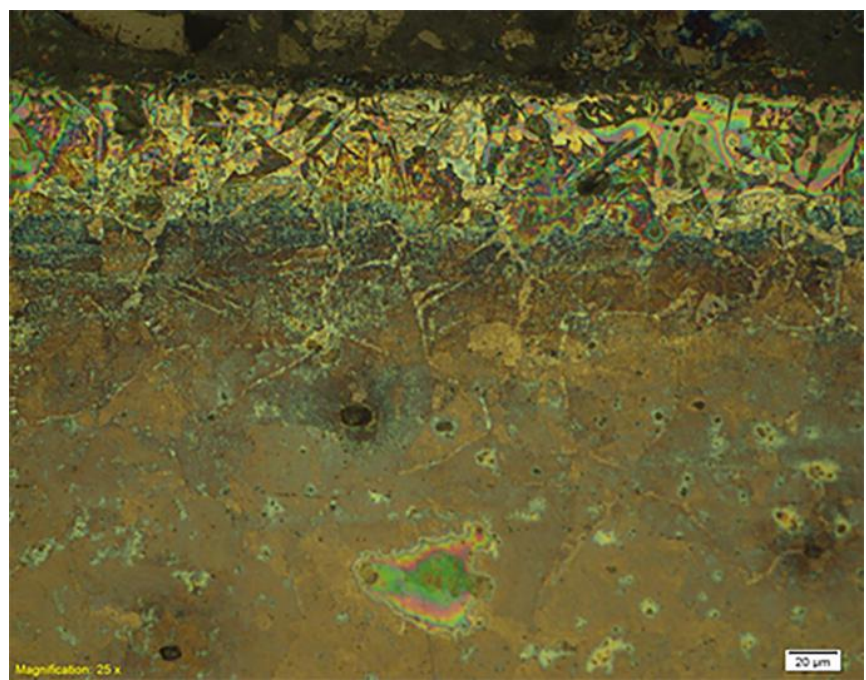

Fig. 2. The microstructure of the coating obtained during SHS process with simultaneous HFC heatinge Sample 2 
Table 2. Initiation SHS processa in cylindrical molded samples from the base mix $\mathrm{Al}+\mathrm{B}_{2} \mathrm{O}_{3}$ by $\mathrm{HFC}$ heatinge

\begin{tabular}{|c|c|c|l|}
\hline $\begin{array}{c}\text { Mass ratio of } \\
\text { reagents }\end{array}$ & $\begin{array}{c}\text { Sample } \\
\text { height } \boldsymbol{L}, \mathbf{m m}\end{array}$ & $\begin{array}{c}\boldsymbol{t}_{\text {ign., }} \\
\mathbf{C}\end{array}$ & \multicolumn{1}{|c|}{$\begin{array}{c}\text { Initiation SHS, } \\
\text { combustion pattern }\end{array}$} \\
\hline $1 / 0.1$ & 20 & - & initiated, slow fading \\
\hline $1 / 0.3$ & 20 & $1.0-1.3$ & initiated, slow \\
\hline $1 / 0.5$ & 20 & $1.3-1.5$ & initiated, fast calm \\
\hline $1 / 0.775^{*}$ & 22 & $1.3-1.5$ & initiated, rapid explosive \\
\hline $1 / 0.8$ & 18 & $1.3-1.7$ & triggered, fast steady \\
\hline $1 / 1$ & 17 & $1.5-2.0$ & triggered, fast steady \\
\hline $1 / 1.2$ & 20 & $2.0-2.2$ & triggered, fast intermittent \\
\hline $1 / 1.5$ & 20 & $2.0-2.5$ & initiated, rapid explosive \\
\hline
\end{tabular}

Note: * stoichiometric composition.

As follows from the data in Table 2, the use of HFC heating makes it possible to initiate and maintain SHS process in all investigated compositions, as with an increasing amount of aluminum powder above the stoichiometric $\mathrm{Al}$ amount, so and $\mathrm{B}_{2} \mathrm{O}_{3}$, in addition, the ignition time of all compositions is reduced and becomes practically constant $(1.5-1.7 \mathrm{sec})$.

SHS process initiation in the studied mixtures at HFC heating starts after a specified period of time from the moment the surface of the steel plate heats up to a temperature $650-750{ }^{\circ} \mathrm{C}$ (dark red heat), and the combustion itself takes place more evenly, quickly and completely.

Since all further SHS process research planned for HFC heatinge was investigated the dependence of SHS initiation in all investigated compositions on the characteristic size of the sample, which, in the case of applying the composition to the steel plate surface in the form of a coating, will be thickness.

For the research, ready-made powder mixtures of reagents differing in mass ratio $\mathrm{Al}$ and $\mathrm{B}_{2} \mathrm{O}_{3}$, moistened with alcohol and stirred until a mushy mass was obtained, which was applied to a previously prepared (cleaned) surface of a steel plate with a size $50 * 100 * 5 \mathrm{~mm}$, stripe width $10 \mathrm{~mm}$ and thickness from 2 to $6 \mathrm{~mm}$, using a special cardboard template. The finished sample was dried and the SHS process with HFC heating initiation was investigated. The research results are presented in Table 3. An example of the obtained coating microstructure is shown in Fig. 3.

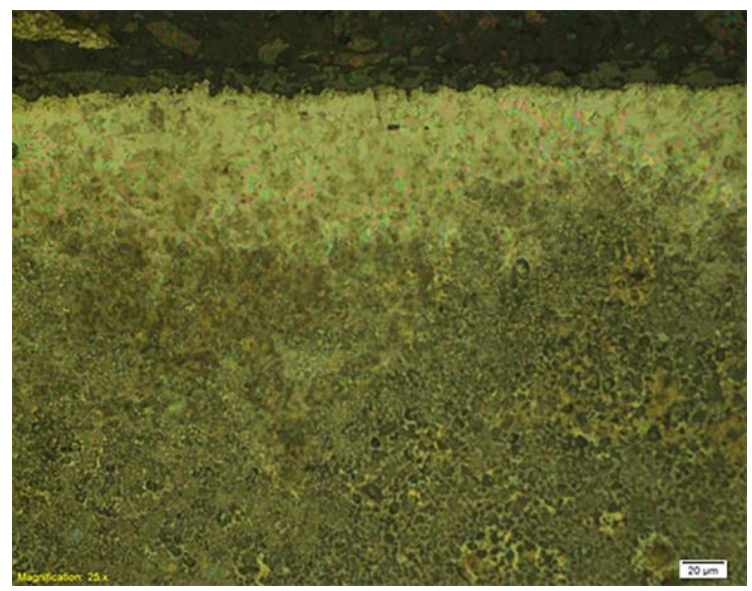

Fig. 3. The microstructure of the coating obtained during SHS process with simultaneous HFC heating Sample 3 
Table 3. SHS process initiation in thin layers from the base mix $\mathrm{Al}+\mathrm{B}_{2} \mathrm{O}_{3}$ at $\mathrm{HFC}$ heating

\begin{tabular}{|c|c|c|l|}
\hline $\begin{array}{c}\text { Mass ratio of } \\
\text { reagents }\end{array}$ & $\begin{array}{c}\text { Thickness of } \\
\text { coating } \boldsymbol{h , ~} \mathbf{~ m m}\end{array}$ & $\begin{array}{c}\boldsymbol{t} \text { ign., } \\
\mathbf{c}\end{array}$ & \multicolumn{1}{|c|}{$\begin{array}{c}\text { SHS initiation, } \\
\text { combustion pattern }\end{array}$} \\
\hline $1 / 0.3$ & 2 & $1.0-1.3$ & initiated, fast calm \\
\hline $1 / 0.5$ & 2 & $1.0-1.3$ & initiated, fast calm \\
\hline $1 / 0.775^{*}$ & 5 & $0.7-1.3$ & initiated, rapid explosive \\
\hline $1 / 0.8$ & 5 & $1.0-1.3$ & initiated, rapid explosive \\
\hline $1 / 1$ & 6 & $1.0-1.3$ & triggered, fast steady \\
\hline $1 / 1.2$ & 6 & $1.5-2.0$ & triggered, fast steady \\
\hline
\end{tabular}

Note: * - stoichiometric composition.

As follows from the data given in Table 3, reliable initiation is achieved SHS process in thin layers for all investigated compositions with a coating layer thickness of up to $6 \mathrm{~mm}$. Obtaining thicker layers is technically difficult (it requires multiple sequential application and drying of each layer, or the use of special equipment) and, in addition, will cause additional difficulties with the placement and heating of a part with such a thick coating HFC inducer.

The ratio of reagents also affects not only the possibility of SHS initiation, but also on the burning rate. To study the base mixture composition dependence on the ratio of reagents in it, cylindrical molded samples of the same height $-20 \mathrm{~mm}$ were prepared, SHS process initiation in which was carried out at HFC heating. The combustion rate was estimated from the combustion time of the sample from one end of the sample to the other. The research results are shown in Figure 4.

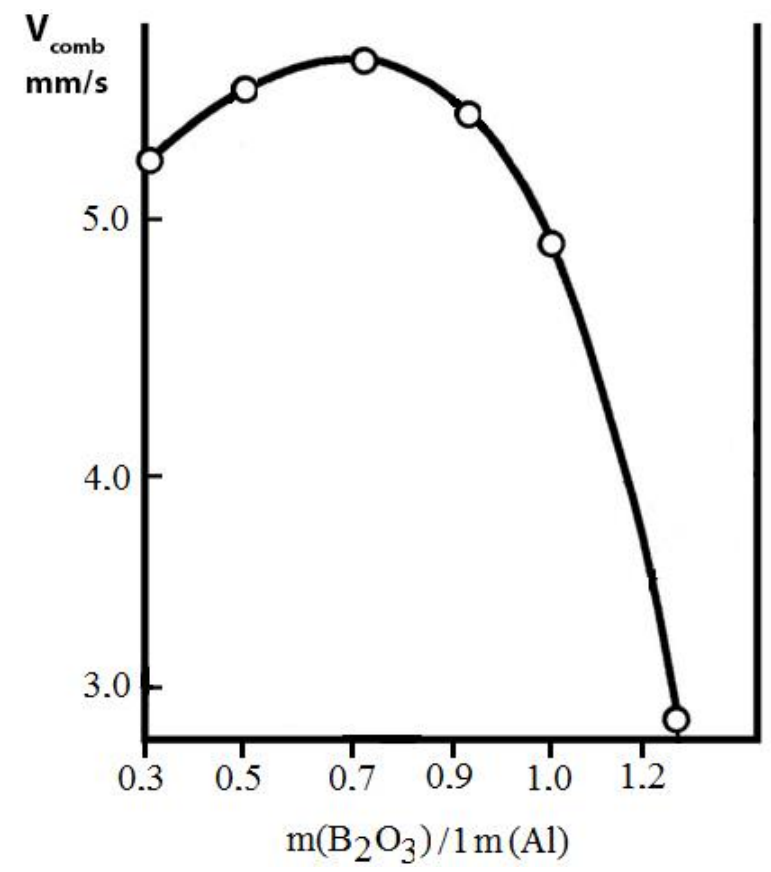

Fig. 4. Dependence of the combustion rate of the base mixture from the mass $\mathrm{B}_{2} \mathrm{O}_{3}$ per mass $\mathrm{Al}$ unit

As follows from Fig. 4, the experimentally obtained dependence of the combustion rate on the mixture composition is close to the theoretical extremal dependence with a maximum in the region of stoichiometric composition, and the maximum deceleration of the combustion rate, up to $2.75 \mathrm{~mm} / \mathrm{sec}$ observed at a 1.5-1.7-fold increase in boron oxide content in the 
mixture, while an almost 2-fold increase in the aluminum content reduces the combustion rate from 5.40 to $5.18 \mathrm{~mm} / \mathrm{sec}$.

The results obtained make it possible to reasonably correct the composition of the base mixture, taking into account the previously obtained results. So, to compensate for the consumption of aluminum for a side reaction with air nitrogen, its content in the mixture can be increased up to 2 times, this will also improve the SHS process initiation conditions. And to reduce the combustion rate and ensure the optimal kinetic conditions for boron synthesis and its consumption for the boriding reaction, the boron oxide content in the base mixture should be increased. In this case, the burning rate of the mixture can be adjusted in the range from 2.75 till $5.40 \mathrm{~mm} / \mathrm{sec}$.

The reagent particles size also affects SHS-compositions' burning rate. Since aluminum is always added to the base mixture in the form of a powder of the grade PAP-1, then, to study the effect of the reagents' particle size on the combustion rate, boron oxide powders with the particle size of the main fraction $<50,50-75,75-100,100-125,>125$ microns were prepared.

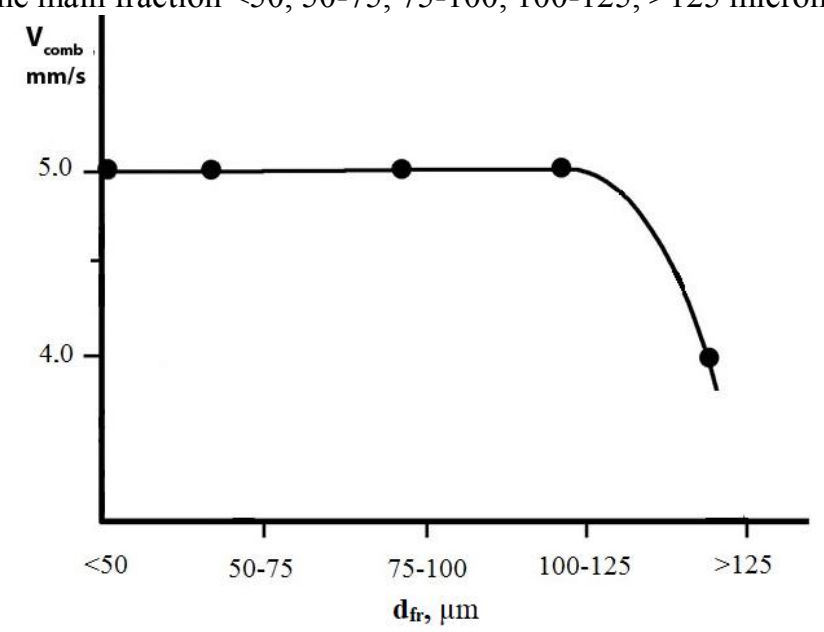

Fig. 5. Dependence of the base mixture combustion rate on the particle size of the main fraction $\mathrm{B}_{2} \mathrm{O}_{3}$

Based on these powders, basic stoichiometric compositions were prepared $\mathrm{B}_{2} \mathrm{O}_{3}+2 \mathrm{Al}$, cylindrical specimens of the same height $-20 \mathrm{~mm}$ were formed from which, on which the burning rate was determined. The research results are presented in Figure 5.

As follows from Figure 5, the particle size of boron (III) oxide in the range of 50-100 $\mu \mathrm{m}$ does not affect the combustion rate of the base composition. This is due to the fact that the melting point of this component does not exceed $450{ }^{\circ} \mathrm{C}$, while the reducing boron oxide is aluminum, it melts at $660^{\circ} \mathrm{C}$, that is, by the time the liquid phase of the reducing metal appears and the reaction begins, all boron oxide melts and passes into the liquid phase.

\section{Modifying the composition of the base mix by flux introduction}

Based on the above-shown studies, the results obtained, the structure and properties of the coatings formed during the flow SHS process at HFC heatinge base mixture on the steel parts surface, it was found that obtaining extended, high-quality boride coatings in such systems is impossible without additional use of flux in SHS-composition.

The flux prepares the steel surface, cleans it from oxides and impurities, protects the metal, SHS-system and active reaction products from interaction with air, contributes to the removal of inactive products and oxidation products from the surface in the form of slag, 
improves heat removal and eliminates overheating and melting of the part during HFC heatinge.

Taking into account the previous studies, it was decided to use a basic flux for induction surfacing: flux P-0.66, consisting of calcined borax, boric anhydride, silico-calcium and welding flux $A H-348 \mathrm{~A}$ in the masses \%: $30 \% \mathrm{Na}_{2} \mathrm{~B}_{4} \mathrm{O}_{7}, 20 \% \mathrm{~B}_{2} \mathrm{O}_{3}, 10 \% \mathrm{CaSi}_{2}$, $40 \% A H-348 A$.

Flux P-0.66 is the main component of borating compositions used in high-speed HFC-boriding, and performs the functions of a transport medium, melting and transferring the boriding process using HFC heatinga from solid-phase to quasi-liquid.

The main component of the flux P-0,66 is a eutectic mixture $\mathrm{B}_{2} \mathrm{O}_{3}$ and $\mathrm{Na}_{4} \mathrm{~B}_{2} \mathrm{O}_{7}$ with a mass ratio of substances 0.66 , which, when heated higher than $500-520{ }^{\circ} \mathrm{C}$ melts and forms complex mixtures of meta- and orthoborates, active boron in cationic $\left(^{+}\right)$and anionic $\left(^{-}\right)$forms and reacts with oxides on the steel surface and other components of the mixture.

Thus, when the base composition is modified with this flux, as the system heats up, liquid phases will gradually form: boric anhydride SHS-mixture $\left(325-450{ }^{\circ} \mathrm{C}\right)$, borate eutectic flux $\mathrm{P}-0,66\left(500-520^{\circ} \mathrm{C}\right)$, and finally aluminum from SHS-mixture $\left(660^{\circ} \mathrm{C}\right)$.

Flux P-0.66, up to the appearance of the aluminum liquid phase first drops will perform cleansing and protective function, since it has pronounced reducing properties, and when flowing SHS processa its use guarantees that the synthesis proceeds in the mode $\mathrm{f}+\mathrm{f}$.

Considering that the flux P-0,66 composition is significant (up to 25-30\%) in the amount of boron oxide in the borate eutectic composition, its content in the modified composition should not exceed $25-30 \%$, since with a higher content of this component, SHS initiation difficulties are possible as well as strong combustion inhibition.

The modified base composition is prepared on the basis of a stoichiometric mixture of components, by adding to them various amounts of the finished calcined flux P-0,66, so that its content in the resulting mixture is: 5, 10, 20 and $30 \%$.

The modified composition in the form of a coating was applied to steel plates $65 \mathrm{G}$, the size $50 * 100 * 5 \mathrm{~mm}$, and the conditions of SHS process initiation were investigated by HFC heating and the dependence of the mixture combustion rate on the flux content in it. A microstructure sample of the obtained coating is shown in Fig. 6.

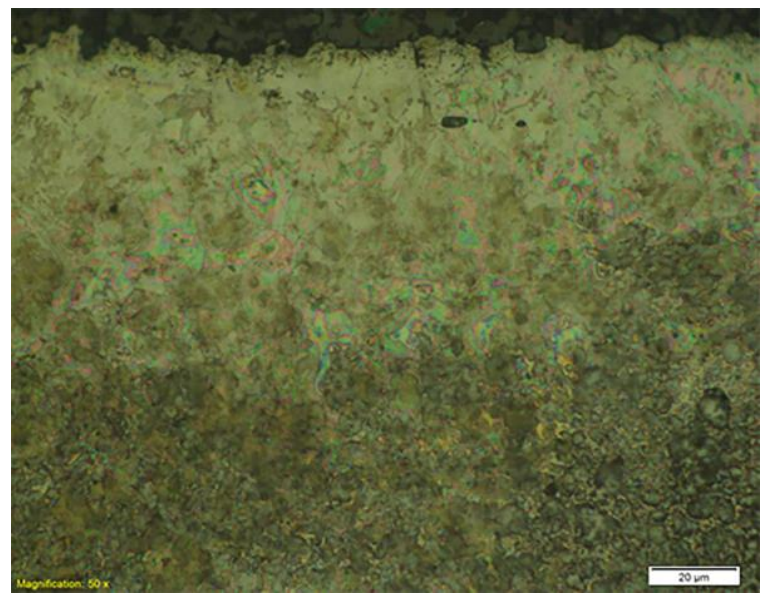

Fig. 6. The microstructure of the coating obtained during SHS process with simultaneous HFC heating Sample 4 (with flux) 
Table 4. SHS process initiation in thin layers from a modified mixture $\mathrm{Al}+\mathrm{B}_{2} \mathrm{O}_{3}$ by $\mathrm{HFC}$ heating

\begin{tabular}{|c|c|c|l|}
\hline Flux content, \% & $\begin{array}{c}\text { Thickness of } \\
\text { coating } h, \mathrm{~mm}\end{array}$ & $\begin{array}{c}t_{\text {ign., }} \\
\mathrm{c}\end{array}$ & \multicolumn{1}{|c|}{$\begin{array}{c}\text { SHS initiation, } \\
\text { combustion pattern }\end{array}$} \\
\hline 5 & 2 & $1.3-1.5$ & initiated, fast \\
\hline 5 & 5 & $1.3-1.5$ & initiated, fast \\
\hline 10 & 3 & $1.5-2.0$ & triggered, fast steady \\
\hline 10 & 5 & $1.7-2.0$ & triggered, fast steady \\
\hline 20 & 5 & $1.7-2.0$ & initiated, slow steady \\
\hline 30 & 5 & $1.7-2.0$ & initiated, slow steady \\
\hline
\end{tabular}

As follows from the data in Table 4, the introduction of up to $10 \%$ flux P- 0.66 practically did not change the basic composition combustion character. The modified composition still ignites easily and quickly burns out, however, the "explosive" nature of combustion disappeared and it became possible to estimate the rate of its combustion, which was from 3 till $3.5 \mathrm{~mm} / \mathrm{sec}$. The modified composition containing from 20 to $30 \%$ flux P- 0.66 is burnt less vigorously. Its burning rate ranged from 1.5 to $2.8 \mathrm{~mm} / \mathrm{c}$, burning became calm. All compounds still initiate their combustion when HFC heating from the heat of a red-hot steel plate, and the time of their ignition became approximately the same.

To experimentally determine the combustion rate dependence of the modified composition on the P-0.66 flux content in it, the cylindrical shaped samples of the same height - $15 \mathrm{~mm}$ were prepared from various compositions, the burning rate of which was calculated from the time of SHS front wave passage of the distance from one end of the cylindrical sample to the other. The results are shown in Figure 7.

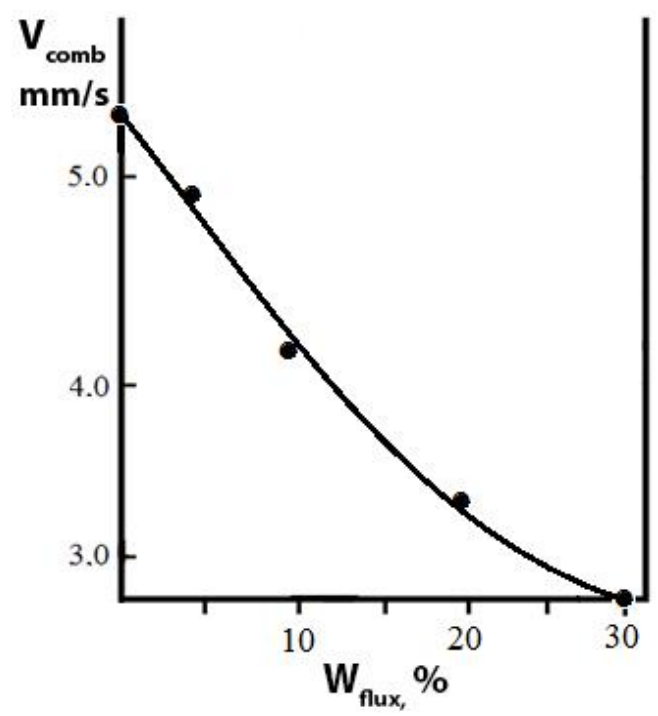

Fig. 7. Dependence of the modified mixture combustion rate on the P-0.66 flux content

\section{Conclusion}

Thus, introducing $2 \mathrm{Al}+\mathrm{B}_{2} \mathrm{O}_{3}$ into the base mixture from 10 till $30 \%$ flux for induction surfacing P-0,66 it is possible to reduce the rate of its burning from 4.2 to $2,8 \mathrm{~mm} / \mathrm{sec}$, which made it possible to match in time SHS process obtaining boron during combustion of a 
modified composition and the high-speed HFC-boriding process for their most effective joint implementation in one system with a wear-resistant boride coating formation. To maintain the stoichiometric ratio of the reagents, taking into account the occurrence of the aluminum nitride formation side reaction, it is necessary to increase the aluminum content in the base mixture by $15-20 \%$, and to reduce the burning rate of such a mixture, increase the boron oxide content for 1.2-1.4 times.

\section{References}

1. P.H. Mayrhofer, C. Mitterer, Progress in Materials Science 51(8), 1032-1114 (2006)

2. J. Musil, Surface and Coatings Technology 125(1-3), 322-330 (2000)

3. S. Vepřek, M.G.J. Vepřek-Heijman, P. Karvankova, Thin Solid Films 476(1), 1-29 (2005)

4. C. Mitterer, F. Holler, F. Ustel, Surface and Coatings Technology 125, 233-239 (2005)

5. G. Erkens, Surface and Coatings Technology 201, 4806-4812 (2007)

6. M. Tului, G. Marino, Surface and Coatings Technology 201, 2103-2108 (2006)

7. A. Yu. Potanin, Obtaining ceramic materials in systems Mo-Si-B and Cr-Al-Si-B by the method of self-propagating high-temperature synthesis (Dissertation for the degree of candidate of technical sciences, National Research Technological University "Moscow Institute of Steel and Alloys", Moscow, 2014).

8. Yu.S. Pogozhev, A.Yu. Potanin, E.A. Levashov, D.Yu. Kovalyev, Universities Proceedings. Powder metallurgy and functional coatings 4, 19-29 (2014)

9. E.A. Levashov, A.S. Rogachev, D.V. Shtansky, International Materials Reviews 62, 203-239 (2017)

10. A.M. Stolin, P.M. Bazhin, A.S. Konstantinov, A.P. Chizhikov, Ceramics International 44, 13815-13819 (2018)

11. S.K. Mishra, Composites Science and Technology 67, 2447-2453 (2007)

12 A. Bhople, S. Paswan, Journal of Refractory Metals \& Hard Materials 43, 7-12 (2014)

13. M. Kholghy, S. Kharatyan, H. Edris, Journal of Alloys and Compounds 502, 491-494 (2010)

14. M. Sakaki, A.K. Behnami, International Journal of Refractory Metals \& Hard Materials 44, 142-147 (2014).

15. S. Zhang, Z.A. Munir, Journal of Materials Science 26, 3685-3688 (1991)

16. V.N. Bloshenko, V.A. Bokii, Combust, Explos. Shock Waves 21, 202-208 (1985)

17. L. Brewer, Atomic Energy Review 7 (1980).

18. D.K. Kondepudi, Journal of Alloys Compounds 505, 43-53 (2010)

19. A.B. Kharatyan, Harutyunyan, Materials Science and Engineering A. 459, 227-232 (2007)

20. S.C. Deevi, International Journal of Refractory Materials 13, 337-342 (1995)

21. H.A. Chatilyan, G.S. Galstyan, Thin Solid Films 516, 4876-4881 (2008)

22. A. Paul, Intermetallics. 19, 1191-1200 (2011)

23. S. Dmitriev, V. Malikov, A. Ishkov, Materials Science Forum 992, 1011-1015 (2020)

24. A Katasonov, V. Malikov, A. Ishkov, E3S Web of Conferences 135, 01067 (2019) 